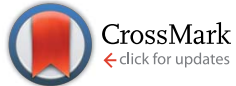

Cite this: Chem. Sci., 2016, 7, 5206

Received 20th February 2016 Accepted 15th April 2016

DOI: $10.1039 / c 6 s c 00798 h$

www.rsc.org/chemicalscience

\section{1,3- and 1,4-Benzdiyne equivalents for regioselective synthesis of polycyclic heterocycles $\uparrow$}

\author{
Takashi Ikawa,* Shigeaki Masuda, Akira Takagi and Shuji Akai*
}

We have devised a novel 1,3-benzdiyne equivalent, capable of quadruple functionalization by sequential benzyne generation and reaction with arynophiles. The key features of this method include the chemoselective generation of two triple bonds in a single benzene ring under fluoride-mediated mild conditions, and the regiocontrol of each benzyne reaction by the substituent next to the triple bond. This method produced various benzo-fused heteroaromatic compounds via reactions with arynophiles, such as furans, azides, and diazo compounds. A validation of the method is given in the convergent synthesis of the antipsychotic drug risperidone. A similar strategy has also been applied to a 1,4benzdiyne equivalent to construct linearly benzo-fused heteroaromatics.

\section{Introduction}

The reactions of benzynes with arynophiles are widely utilized for introducing substituents to adjacent carbons of benzene rings. ${ }^{1}$ The direct installation of fused rings onto benzenes is an advantage specific to the benzyne reaction and is not possible through other methods. Furthermore, a variety of new arynophiles have been recently reported, enriching the diversity of the method. ${ }^{2}$

The reactions of benzdiynes, possessing two triple bonds in a single benzene ring, and two arynophiles, would provide a few-step synthesis for the convergent preparation of multifused benzenes. However, benzdiynes are observed only under gas-phase conditions due to their extreme instability, ${ }^{3}$ and it would be impossible to react one with two different arynophiles for the synthesis of unsymmetrically fused benzene rings.

An alternative approach is to use benzdiyne equivalents, where two benzynes are generated sequentially in one pot to provide substituted acenes and polycyclic aromatic compounds. If we could control the regiochemistry of consecutive benzyne reactions, starting from benzdiyne equivalents, each with different arynophiles, we could produce a wide range of multiring fused unsymmetrical aromatic compounds. ${ }^{4}$ However, only a limited number of such reactions have been reported, and most of them require several steps for functional group transformations to generate the second benzyne., ${ }^{5,6}$ Therefore, the development of more sophisticated benzdiyne equivalents is needed to facilitate two-step sequential benzyne reactions. Crucial factors in the design of these benzdiyne equivalents

Graduate School of Pharmaceutical Sciences, Osaka University, 1-6 Yamadaoka, Suita, Osaka 565-0871, Japan.E-mail: ikawa@phs.osaka-u.ac.jp; akai@phs.osaka-u.ac.jp $\uparrow$ Electronic supplementary information (ESI) available. See DOI: $10.1039 / \mathrm{c} 6 \mathrm{sc} 00798 \mathrm{~h}$ include suitable functional groups which enable the generation of the second benzyne without further transformations, and a way to control the regiochemistry of each benzyne reaction. The work of Suzuki et al. involving their original 1,4-benzdiyne equivalent meets these requirements, which uses $n$-butyllithum to generate the benzynes. ${ }^{\boldsymbol{b}}{ }^{\boldsymbol{b}}$ Very recently, Peña et al. have demonstrated that triple bonds were sequentially generated twice under fluoride-mediated mild conditions from 1,4-benzdiyne equivalents and reacted with two different arynophiles in both stepwise and one-pot manners. ${ }^{7}$ In contrast, there have been no reports of a suitable 1,3-benzdiyne equivalent. ${ }^{5,8,9}$

We have attempted sequential benzyne reactions starting from 1,3-benzdiyne equivalents $\mathbf{1}$, with various arynophiles (Scheme 1). This method was designed to afford unsymmetrically substituted polycyclic aromatic compounds 3, possessing consecutive fused-rings, as are often seen in material and pharmaceutical science. ${ }^{\mathbf{1 0}}$ While compounds like 3 have been

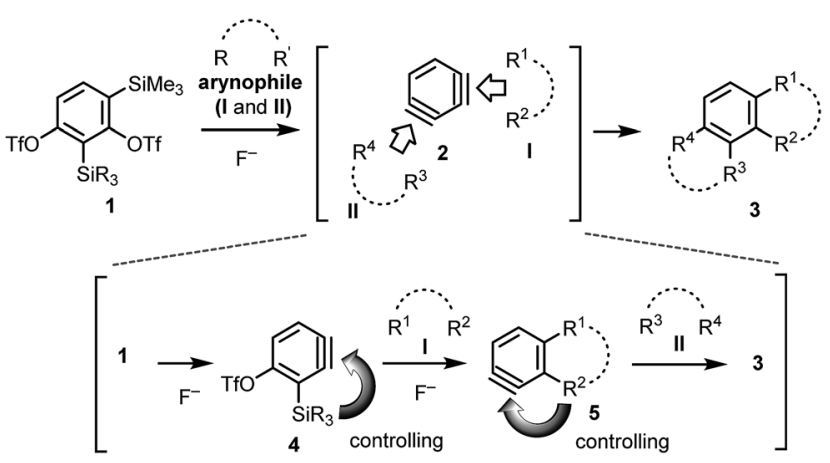

Scheme 1 Design of benzdiyne equivalent 1 that can sequentially generate two triple bonds in a single benzene ring and control the regiochemistry of two benzyne reactions by the substituents next to each triple bond. 
mainly synthesized via linear, multi-step routes, our approach is convergent and rapid, proceeding by the combination of $\mathbf{1}$ and two different arynophiles ( $\mathbf{I}$ and $\mathbf{I I}$ ), and allows a rational design for the production of a library of compounds. We were particularly interested in its application to the synthesis of benzofused heterocycles for medicinal chemistry. Therefore, we planned reactions using heteroatomic 1,3-dipoles, such as azides, nitrones, diazo compounds, and nitrile oxides, as the arynophiles.

We aimed to develop a synthetic methodology in which (1) two benzynes (4 and 5) are chemoselectively generated in a stepwise manner without any additional functionalization steps, (2) each benzyne is generated under mild conditions using a fluoride, and (3) the two cycloaddition reactions of $\mathbf{4}$ and 5 with I and II proceed in a highly regioselective manner (Scheme 1). In this article, we report the preparation of a new 1,3-benzdiyne equivalent $\mathbf{1 b}\left[\mathrm{SiR}_{3}=\mathrm{Si}(t-\mathrm{Bu}) \mathrm{Me}_{2}\right]$, and a method for the preparation of unsymmetrical, angular, and multi-ring fused heterocyclic compounds 3 , which satisfies the above criteria. One significant advantage of this method is the high regioselectivity of both benzyne reactions, in which the first step is controlled by the traceless directing group, $\mathrm{R}_{3} \mathrm{Si}$ (ref. 11) of 4 , and the second step by the cyclic systems ${ }^{12}$ of 5 .

\section{Results and discussion}

We synthesized two 1,3-benzdiyne equivalents, $\mathbf{1 a}$ and $\mathbf{1 b}$, which were treated with CsF in the presence of 2,4-dimethylfuran 6a. The reaction of $1 \mathrm{a}$ with $\mathbf{6 a}$ produced the undesired cycloaddition product 8 via benzyne 7 (Scheme 2). However, the reaction of $\mathbf{1 b}$ afforded the desired cycloaddition product 10a (78\% yield) through the Diels-Alder reaction of the expected benzyne 4a with 6a. An important observation is that the double cycloaddition product 3a was not detected by GC analysis of the crude reaction mixture after $30 \mathrm{~min}$ (see ESI $\dagger$ ). This may be due to the lower reactivity of the $\mathrm{Me}_{2}(t-\mathrm{Bu}) \mathrm{Si}$ group, even in the presence of excess CsF and 6a. The generation of the second benzyne $5 \mathbf{a}$ was achieved after long reaction time $(19 \mathrm{~h})$ under the same reaction conditions using $\mathrm{CsF}$ to give $3 \mathrm{a}$ in $90 \%$ isolated yield.

We attempted to synthesize compounds $\mathbf{3 b} \mathbf{b}-\mathbf{f}$ through stepwise benzyne cycloaddition reactions from $\mathbf{1 b}$ (Table 1). All reactions of 3-silylbenzyne $4 \mathbf{a}$ with arynophiles $\mathbf{6 b}-\mathbf{e}$ provided cycloaddition products $\mathbf{1 0}$ with good regioselectivities due to synergetic effect of the neighboring $\mathrm{Me}_{2}(t-\mathrm{Bu}) \mathrm{Si}$ (ref. 11f) and the distant triflyloxy (TfO) groups. ${ }^{13}$ Among them, unexpected proximal regioselectivity (proximal-10d : distal-10d $=78: 22$ ) was observed in the reaction between 3-silylbenzyne 4a and nitrone 6d (entry 4-1), which was opposite to the previously reported reactions of 3-silylbenzynes with nitrones (for structural determinations, see ESI $\dagger$ ). ${ }^{11 f-h}$ This result is probably due to the inductively electron-withdrawing effect of the TfO group at C4. ${ }^{13 a}$ The reaction of $\mathbf{4 a}$ with sydnone $6 \mathbf{e}$ to give distal- $2 \mathrm{H}^{-}$ indazole 10e selectively (entry 5-1) is particularly noteworthy, as the reactions of unsymmetrical benzynes such as 3-methoxybenzyne with sydnones have been reported to afford mixtures of regioisomers in $1: 1$ ratio. ${ }^{2 f}$ The reaction of benzynes 5 with arynophiles $\mathbf{6 b}$ and $\mathbf{6 f}-\mathbf{g}$ provided polycyclic compounds $\mathbf{3 b} \mathbf{b}-\mathbf{f}$. This is the first report of the generation and reaction of 4,5benzotriazolyne $\mathbf{5 b}$ (entry 2-2), 6,7-benzisoxazolyne $\mathbf{5 c}$ (entry 32), 4,5-benzisoxazolinyne 5d (entry 4-2), and 6,7-2H-indazolyne 5e (entry 5-2). The regioselectivity of these reactions is higher than that of sterically similar 4,5-indolyne (see preliminary theoretical discussion of these regioselectivities in ESI $\dagger$ ). ${ }^{12 a, b}$ The reactions of $5 \mathbf{c}$ with $6 \mathbf{b}$ and $5 \mathbf{e}$ with $6 \mathrm{~g}$ provided distal-3d and proximal-3f exclusively (entries 3-2 and 5-2).

Next, one-pot sequential benzyne cycloadditions from $\mathbf{1 b}$ were demonstrated for the synthesis of angular tricyclic heterocycles $\mathbf{3}$ without isolating $\mathbf{1 0}$ (Scheme 3). After a mixture of $1 \mathbf{b}$ (1.0 equiv.), benzyl azide $6 \mathbf{b}$ (1.1 equiv.) and CsF (4.0 equiv.) in $\mathrm{MeCN}$ was stirred at room temperature for 30 min, 2-methylfuran $\mathbf{6 h}$ (3.0 equiv.) and 18-crown-6 (4.0 equiv.) were added and then the reaction mixture was stirred for $16 \mathrm{~h}$ at $0{ }^{\circ} \mathrm{C}$ (Scheme 3-1). Gratifyingly, proximal-3g was obtained as a main product (proximal-3g: distal-3g $=$ $63: 37$, total 56\%). The tricyclic compound, distal-3e was also synthesized as the predominant product (distal-3e : proximal-3e $=93: 7$, total $38 \%$ ) by a similar one-pot combination of arynophiles, nitrone 6d and 6b (Scheme 3-2). The yield and regioselectivity of these products were comparable to those obtained by the stepwise method (Table 1, entries 4-1 and 4-2).

We applied these findings to the convergent synthesis of the antipsychotic drug risperidone $\mathbf{1 4}$ (Scheme 4). The silylbenzyne $4 \mathbf{a}$ and a nitrile oxide $\mathbf{6 i}$ (ref. $2 e$ ) were simultaneously generated

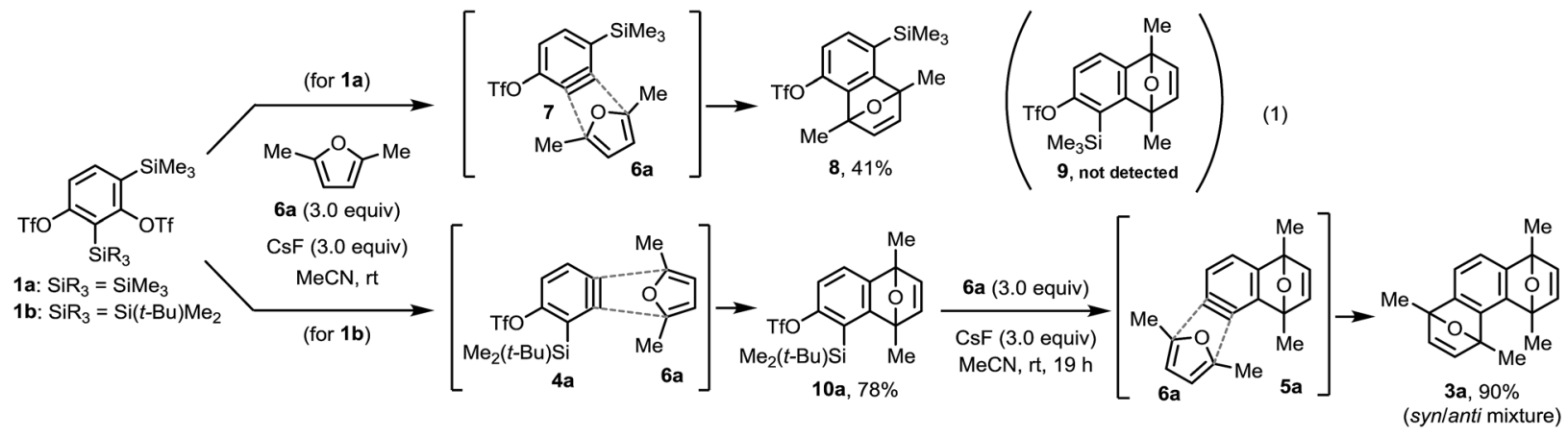

Scheme 2 Sequential benzyne generation from benzdiyne equivalents $1 \mathrm{a}$ and $1 \mathrm{~b}$ followed by Diels-Alder reaction with furan $6 \mathrm{a}$. 
Table 1 Reactions of $1 \mathrm{~b}$ with two different arynophiles 6 for the synthesis of angular polycycles $3^{a}$

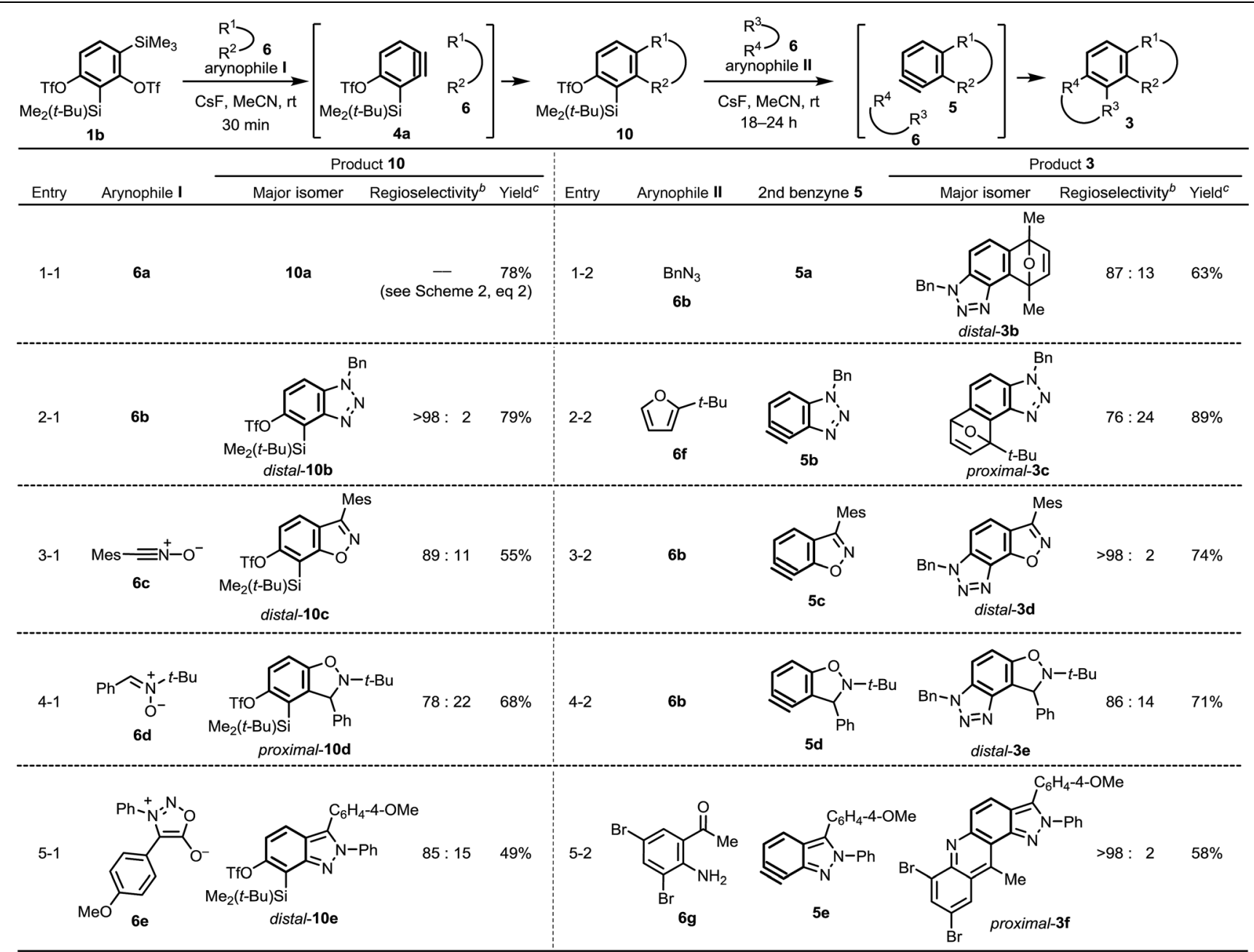

${ }^{a}$ Conditions: 1 b or 10 (1.0 equiv.), arynophile (3.0 equiv.), CsF (3.0 equiv.) in MeCN at rt. ${ }^{b}$ The ratio of major and minor products was determined by ${ }^{1} \mathrm{H}$ NMR. ${ }^{c}$ Total isolated yield of distal-10 (or distal-3) and its regioisomer proximal-10 (or proximal-3). $\mathrm{Mes}^{2}=\mathrm{C}_{6} \mathrm{H}_{2}-2,4,6-\mathrm{Me}_{3}$.

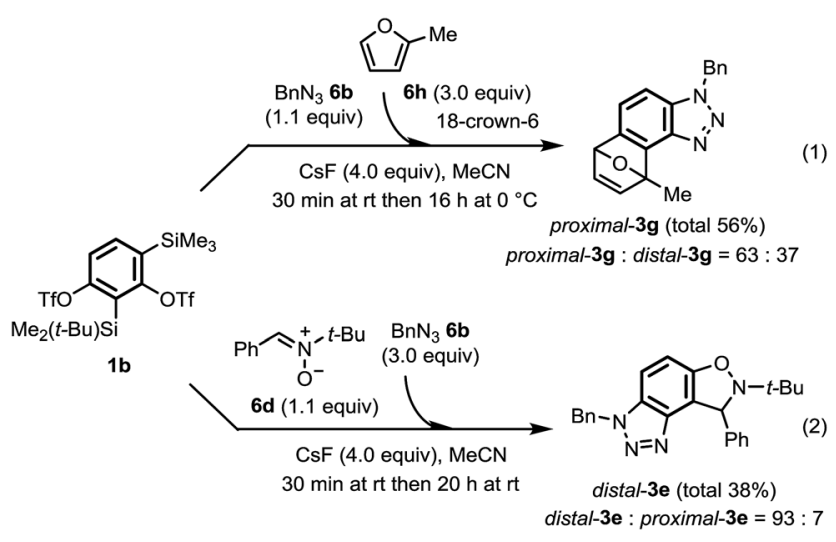

Scheme 3 One-pot synthesis of unsymmetrical angular heterocycles $3 \mathrm{~g}$ and $3 \mathrm{e}$.

from a mixture of $\mathbf{1 b}$ and a chloro-oxime $\mathbf{1 1}$ and then reacted in situ to form distal-10f as a single regioisomer. The next reaction of 6,7-benzisoxazolyne 5f, generated by $\mathrm{BnMe}_{3} \mathrm{NF}$ (ref. 14 and 15) and a fluoride $\mathbf{6 j}$, provided $3 \mathbf{h}$ with excellent regioselectivity. Finally, the synthesis was completed by the $N$-deprotection of $\mathbf{3 h}$ to give 12 and the alkylation with $13 .^{16}$ This result suggests that 1b should be useful tool for the expeditious divergent synthesis of a wide variety of biologically active compounds and their derivatives by choosing different arynophiles $\mathbf{6}$ once $\mathbf{1 b}$ become easily available (for the first synthesis of $\mathbf{1 b}$, see ESI $\dagger$ ).

We also report the synthesis of linearly fused, unsymmetrical polycyclic aromatics 19 using 15 (ref. 17-19) as a 1,4-benzdiyne equivalent (Table 2). The first benzyne generation proceeds using CsF at room temperature in MeCN for a short time, under which conditions, generation of the second benzyne does not occur (see ESI $\dagger$ ). The mono-cycloaddition products 17, obtained as a mixture of two regioisomers, were subjected to the second reaction with arynophiles II, without separation of the regioisomers, ${ }^{20}$ to afford the multicyclic compounds 19. Due to the dual effect of the TfO group ${ }^{13 a}$ and $\mathrm{Me}_{3} \mathrm{Si}_{\text {group }}{ }^{11 e}$ of 16, the all first benzyne reactions proceeded in a regioselective manner 


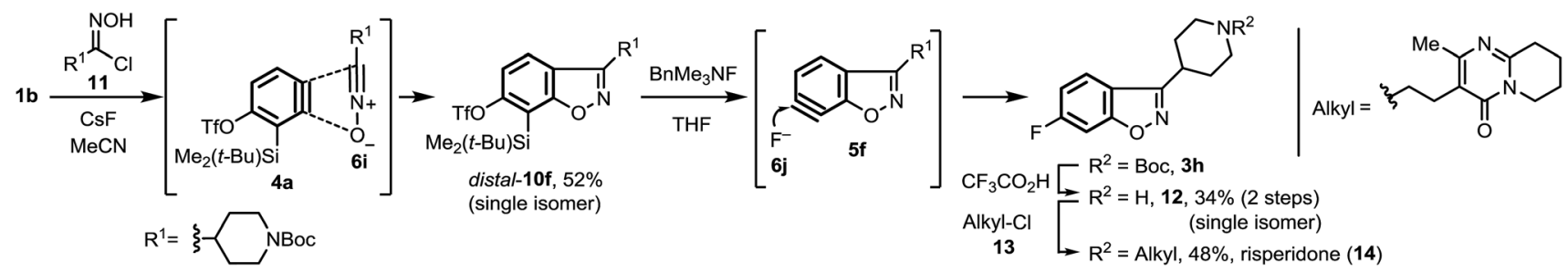

Scheme 4 Application of 1,3-benzdiyne equivalent $1 \mathrm{~b}$ to the synthesis of risperidone 14

Table 2 Reactions of a 1,4-benzdiyne equivalent 15 with two different arynophiles 6 for the synthesis of linear polycycles $19^{a}$

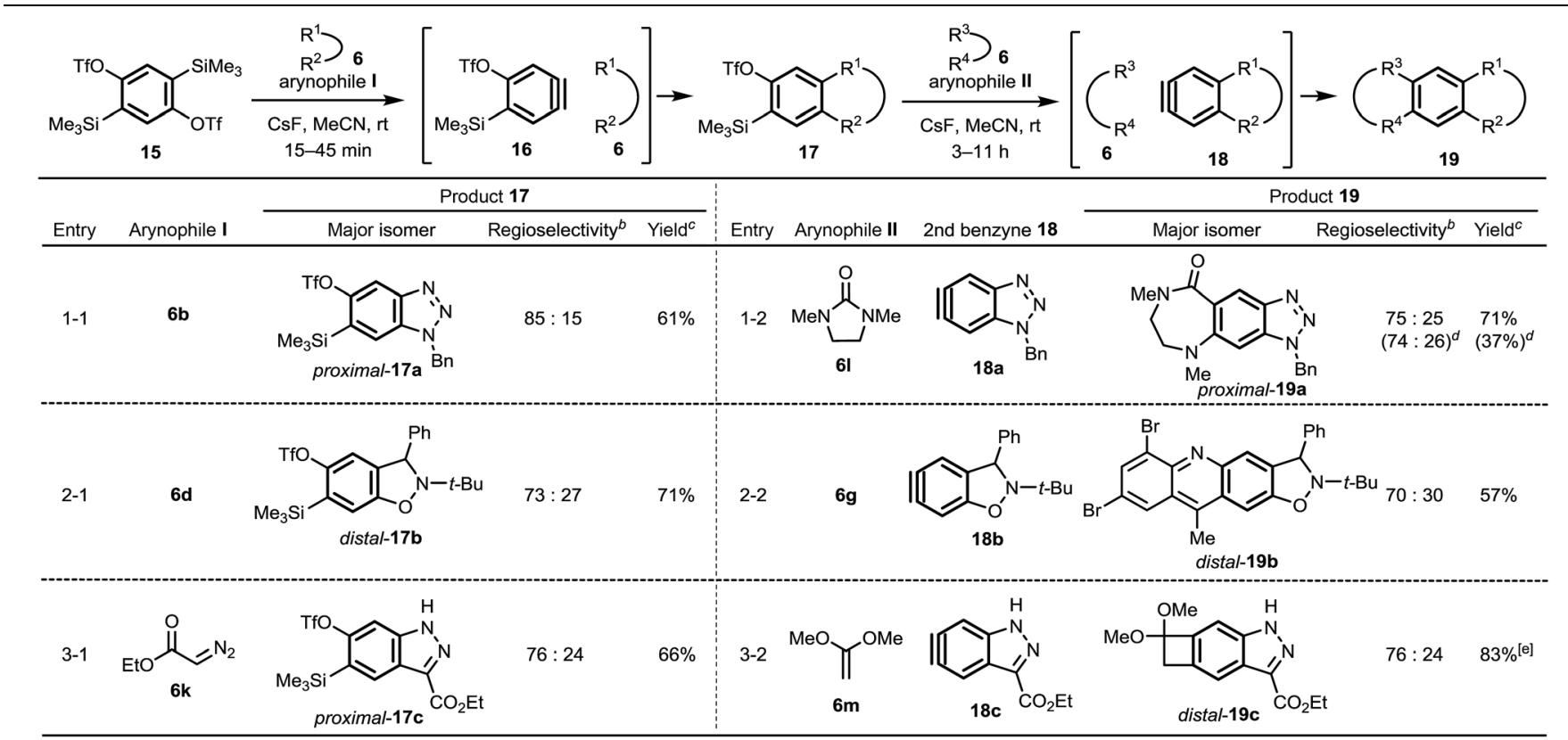

${ }^{a}$ Conditions: 15 or 17 (1.0 equiv.), arynophile 6 (3.0 equiv.), CsF (3.0 equiv.) in MeCN at rt. ${ }^{b}$ A ratio of major and minor products was determined by ${ }^{1} \mathrm{H}_{\mathrm{NMR}}{ }^{c}$ Total isolated yield of distal-17 (or distal-19) and its regioisomer proximal-17 (or proximal-19). ${ }^{d}$ One-pot reaction conditions: 15 (1.0 equiv.), $6 \mathbf{b}$ (1.1 equiv.), $6 \mathbf{1}$ (3.0 equiv.), CsF (4.0 equiv.) in MeCN (0.1 M) at rt for $30 \mathrm{~min}$ and then at rt for $14 \mathrm{~h}$. The yield was calculated based on $15 .{ }^{e}$ Isolated as a corresponding ketone $19 \mathrm{c}^{\prime}$ after the hydrolysis of acetal 19c.

beyond expectation (Table 2, entries 1-1, 2-1 and 3-1), although these selectivities were only a little lower than those of the 1,3benzdiyne equivalent $\mathbf{1 b}$ (see, Table 1). Interestingly, the second benzyne reactions also regioselectively provided cycloaddition products 19 probably because of the inductive effect of heteroatoms such as nitrogen and oxygen constructing heterocycles (entries 2-2 and 3-2). These results provide useful information for regioselectivity control of benzyne cycloadditions from distant positions. Importantly, the one-pot synthesis of a linear tricyclic compound 19a from 15, $\mathbf{6 b}$ and 61 was also successfully achieved (see entry 1-2).

\section{Conclusions}

In conclusion, we have developed a novel synthetic route to multi-ring fused heterocycles by the combination of benzdiyne equivalents and arynophiles. In this study, the newly generated azole-fused benzynes were found to exhibit higher regioselectivities than those of sterically similar 4,5 -indolyne. ${ }^{\mathbf{1 2 b}}$ This method has facilitated the convergent synthesis of the antipsychotic risperidone. Therefore, we believe that this synthetic methodology will be invaluable to drug discovery. Work is ongoing into easier, scalable synthetic methods for these benzdiyne equivalents, ${ }^{19}$ analysis of the origin of the regioselectivity (see ESI $\dagger$ ), and applications to medicinal chemistry.

\section{Acknowledgements}

We thank Dr N. Kotoku of Osaka University for analyzing NMR data. This work was financially supported by the JSPS KAKENHI (grant numbers 23790017, 24390005 and 25460018) and Grantin-Aid for JSPS (grant number 15J06024), the Platform for Drug Discovery, Informatics, and Structural Life Science from the MEXT and the Hoansha foundation. 


\section{References}

1 For selected reviews on benzynes, see: $(a) \mathrm{H}$. Pellissier and M. Santelli, Tetrahedron, 2003, 59, 701; (b) A. M. Dyke, A. J. Hester and G. C. Lloyd-Jones, Synthesis, 2006, 4093; (c) R. Sanz, Org. Prep. Proced. Int., 2008, 40, 215; (d) A. Bhunia, S. R. Yetra and A. T. Biju, Chem. Soc. Rev., 2012, 41, 3140; (e) P. M. Tadross and B. M. Stoltz, Chem. Rev., 2012, 112, 3550; (f) C. Wu and F. Shi, Asian J. Org. Chem., 2013, 2, 116; (g) A. V. Dubrovskiy, N. A. Markina and R. C. Larock, Org. Biomol. Chem., 2013, 11, 191; (h) S. Yoshida and T. Hosoya, Chem. Lett., 2015, 44, 1450. For recently published very important paper on benzyne chemistry $(i)$ T. R. Hoye, B. Baire, D. Niu, P. H. Willoughby and B. P. Woods, Nature, 2012, 490, 208.

2 For selected papers on benzyne reactions with new arynophiles, see: (a) T. Jin and Y. Yamamoto, Angew. Chem., Int. Ed., 2007, 46, 3323; (b) F. Shi, J. P. Waldo, Y. Chen and R. C. Larock, Org. Lett., 2008, 10, 2409; (c) D. C. Rogness and R. C. Larock, J. Org. Chem., 2010, 75, 2289; (d) C. Spiteri, S. Keeling and J. E. Moses, Org. Lett., 2010, 12, 3368; (e) A. V. Dubrovskiy and R. C. Larock, Org. Lett., 2010, 12, 1180; $(f)$ Y. Fang, C. Wu, R. C. Larock and F. Shi, J. Org. Chem., 2011, 76, 8840; $(g)$ M. E. Hayes, H. Shinokubo and R. L. Danheiser, Org. Lett., 2005, 7, 3917.

3 For selected papers on benzdiynes, see: (a) T. Sato, H. Niino and A. Yabe, J. Am. Chem. Soc., 2003, 125, 11936; (b) T. Sato and H. Niino, Aust. J. Chem., 2010, 63, 1048.

4 For a review on the synthesis of acenes using aromatic ynes including benzdiynes, see: (a) J. Li and Q. Zhang, Synlett, 2013, 24, 686; (b) D. Pérez, D. Peña and E. Guitián, Eur. J. Org. Chem., 2013, 5981.

5 For papers on the 1,3-benzdiyne equivalents that generate two triple bonds by a step-by-step manner, see: (a) T. Hamura, Y. Ibusuki, K. Sato, T. Matsumoto, Y. Osamura and K. Suzuki, Org. Lett., 2003, 5, 3551; (b) Y.-L. Chen, J.-Q. Sun, X. Wei, W.-Y. Wong and A. W. M. Lee, J. Org. Chem., 2004, 69, 7190; For papers on the 1,3,5-benztriyne equivalents, see: (c) T. Hamura, Y. Ibusuki, H. Uekusa, T. Matsumoto and K. Suzuki, J. Am. Chem. Soc., 2006, 128, 3534; (d) T. Hamura, Y. Ibusuki, H. Uekusa, T. Matsumoto, J. S. Siegel, K. K. Baldridge and K. Suzuki, J. Am. Chem. Soc., 2006, 128, 10032.

6 For selected papers on 1,4-benzdiyne equivalents that generate two triple bonds by a step-by-step manner, see: $(a)$ S.-H. Chan, C.-Y. Yick and H. N. C. Wong, Tetrahedron, 2002, 58, 9413; (b) T. Hamura, T. Arisawa, T. Matsumoto and K. Suzuki, Angew. Chem., Int. Ed., 2006, 45, 6842; (c) D. Chun, Y. Cheng and F. Wudl, Angew. Chem., Int. Ed., 2008, 47, 8380; (d) K. Gondo and T. Kitamura, Adv. Synth. Catal., 2014, 356, 2107; (e) K. Gondo, J. Oyamada and T. Kitamura, Heterocycles, 2015, 90, 681. See also ref. $5 b$.

7 (a) B. Schuler, S. Collazos, L. Gross, G. Meyer, D. Pérez, E. Guitián and D. Peña, Angew. Chem., Int. Ed., 2014, 53, 9004; (b) D. Rodríguez-Lojo, D. Peña, D. Pérez and E. Guitián, Synlett, 2015, 26, 1633; (c) N. Pavliček,
B. Schuler, S. Collazos, N. Moll, D. Pérez, E. Guitián, G. Meyer, D. Peña and L. Gross, Nat. Chem., 2015, 7, 623; For related example of 2,6-naphthalenediyne synthon, see: (d) D. Rodríguez-Lojo, D. Pérez, D. Peña and E. Guitián, Chem. Commun., 2015, 51, 5418.

8 An activation with a strong acid, such as TfOH (ref. $5 b$ ) and $\mathrm{BF}_{3} \cdot \mathrm{OEt}_{2},{ }^{\boldsymbol{6} d}$ was necessary before the generation of each benzyne using a fluoride.

9 For related work on iterative generation of benzynes, see: $(a)$ C.-J. Frank Du and H. Hart, J. Org. Chem., 1987, 52, 4311; (b) H. Hart and T. Ghosh, Tetrahedron Lett., 1988, 29, 881; (c) J. Shi, D. Qiu, J. Wang, H. Xu and Y. Li, J. Am. Chem. Soc., 2015, 137, 5670.

10 For selected papers on angular aromatic compounds, see; (a) S. Blättermann, L. Peters, P. A. Ottersbach, A. Bock, V. Konya, C. D. Weaver, A. Gonzalez, R. Schröder, R. Tyagi, P. Luschnig, J. Gäb, S. Hennen, T. Ulven, L. Pardo, K. Mohr, M. Gütschow, A. Heinemann and E. Kostenis, Nat. Chem. Biol., 2012, 8, 631; (b) C.-K. Ryu, J.-H. Nho, G. Jin, S. Y. Oh and S. J. Choi, Chem. Pharm. Bull., 2014, 62, 668; (c) L. Nagarapu, H. R. Vulupala, R. Bantu, Y. Sajja and J. B. Nanubolu, Tetrahedron: Asymmetry, 2014, 25, 578.

11 For selected papers on silyl group directed nucleophilic additions of benzynes, see: (a) C. Heiss, F. Cottet and M. Schlosser, Eur. J. Org. Chem., 2005, 5236; (b) V. Diemer, M. Begaud, F. R. Leroux and F. Colobert, Eur. J. Org. Chem., 2011, 341; (c) T. Ikawa, T. Nishiyama, T. Shigeta, S. Mohri, S. Morita, S.-I. Takayanagi, Y. Terauchi, Y. Morikawa, A. Takagi, Y. Ishikawa, S. Fujii, Y. Kita and S. Akai, Angew. Chem., Int. Ed., 2011, 50, 5674; (d) S. M. Bronner, J. L. Mackey, K. N. Houk and N. K. Garg, J. Am. Chem. Soc., 2012, 134, 13966; (e) H. Yoshida, R. Yoshida and K. Takaki, Angew. Chem., Int. Ed., 2013, 52, 8629; For silyl group directed [4+2] cycloadditions,see; $(f)$ S. Akai, T. Ikawa, S.-I. Takayanagi, Y. Morikawa, S. Mohri, M. Tsubakiyama, M. Egi, Y. Wada and Y. Kita, Angew. Chem., Int. Ed., 2008, 47, 7673; For silyl group directed (3 + 2) cycloadditions, see: $(g)$ T. Matsumoto, T. Sohma, S. Hatazaki and K. Suzuki, Synlett, 1993, 843; (h) M. Dai, Z. Wang and S. J. Danishefsky, Tetrahedron Lett., 2008, 49, 6613; (i) T. Ikawa, A. Takagi, M. Goto, Y. Aoyama, Y. Ishikawa, Y. Itoh, S. Fujii, H. Tokiwa and S. Akai, J. Org. Chem., 2013, 78, 2965.

12 For selected fused five-membered ring directed benzyne reactions, see: (a) A. N. Garr, D. Luo, N. Brown, C. J. Cramer, K. R. Buszek and D. VanderVelde, Org. Lett., 2010, 12, 96; (b) G.-Y. J. Im, S. M. Bronner, A. E. Goetz, R. S. Paton, P. H.-Y. Cheong, K. N. Houk and N. K. Garg, J. Am. Chem. Soc., 2010, 132, 17933; For various fused ring directed benzyne reactions, see: (c) A. E. Goetz, S. M. Bronner, J. D. Cisneros, J. M. Melamed, R. S. Paton, K. N. Houk and N. K. Garg, Angew. Chem., Int. Ed., 2012, 51, 2758.

13 For unique 3- or 4-TfO group-directed benzyne reactions, see: (a) T. Ikawa, H. Kaneko, S. Masuda, E. Ishitsubo, H. Tokiwa and S. Akai, Org. Biomol. Chem., 2015, 13, 520; 
(b) S. Yoshida, K. Uchida, K. Igawa, K. Tomooka and T. Hosoya, Chem. Commun., 2014, 50, 15059. See also ref. $9 c$. 14 The use of $\mathrm{BnMe}_{3} \mathrm{NF}$ as an anhydrous fluoride source was necessary both for the benzyne generation and for the nucleophilic addition of the fluoride because a significant amount of the phenol derivative was formed when $\mathrm{Bu}_{4} \mathrm{NF} \cdot(t-\mathrm{BuOH})_{4}$ was used. The latter results are probably owing to the nucleophilic addition of contaminant water to generate benzyne $\mathbf{5 f} .^{15}$

15 For fluorination reactions of benzynes with fluorides, see; T. Ikawa, S. Masuda, T. Nishiyama, A. Takagi and S. Akai, Aust. J. Chem., 2014, 67, 475.

16 A. V. Dubrovskiy, P. Jain, F. Shi, G. H. Lushington, C. Santini, P. Porubsky and R. C. Larock, ACS Comb. Sci., 2013, 15, 193.

17 2,4-Bis(trimethylsilyl)-1,3-bis(trifluoromethanesulfonyloxy) benzene 15 has been recognized as a one-step 1,4-benzdiyne equivalent that consecutively generates two triple bonds at the $\mathrm{C} 1$ and $\mathrm{C} 4$ positions of a single benzene to react with two equivalents of a single arynophile. ${ }^{4,18}$ Peña et al. have recently used $\mathbf{1 5}$ as a quasi-step-by-step benzdiyne equivalent for the synthesis of polyaromatic hydrocarbon (PAH), in which the second benzyne was not generated because of the precipitation of the mono-cycloaddition product $^{7 \boldsymbol{a}-\boldsymbol{c}}$.

18 (a) H. M. Duong, M. Bendikov, D. Steiger, Q. Zhang, G. Sonmez, J. Yamada and F. Wudl, Org. Lett., 2003, 5, 4433; (b) D. Rodríguez-Lojo, A. Cobas, D. Peña, D. Pérez and E. Guitián, Org. Lett., 2012, 14, 1363.

19 We have developed an improved, 3-step synthesis of 15 with $70 \%$ overall yield, while the reported method required 4 steps and gave $13 \%$ overall yield. ${ }^{18 a}$ Recently, another improved method was reported which required 3 steps in $59 \%$ overall yield ${ }^{7 c}$ (see ESI $\dagger$ ).

20 Both regioisomers 17 should be transformed to the same benzynes 18. 